\title{
Factors (gender, age, social status, and income) affecting the satisfaction of pharmacy career in Saudi Arabia
}

\author{
Yousef Ahmed Alomi*, (D) General \\ Administration of Pharmaceutical Care, \\ Ministry of Health, Riyadh, SAUDI ARABIA. \\ Faiz Abdullah Bahadig RPH, Depart- \\ ment of Pharmaceutical Care, King Abdu- \\ laziz Medical City-WR-Jeddah, Ministry of \\ National Guard, SAUDI ARABIA. \\ Reem Saad Alsubaie, Pharmacy Services, \\ Prince Sultan Military Medical City, Riyadh, \\ SAUDI ARABIA. \\ Bayan Ibrahim Alghuraybi, Pharmacy \\ Services, Prince Sultan Military Medical \\ City, Riyadh, SAUDI ARABIA. \\ Budoor Emad Aloumi, Pharmaceutical \\ Care Services, Ministry of National Guard \\ - Health Affairs. KAMC - Central Region, \\ SAUDI ARABIA.
}

\section{Correspondence:}

Dr. Yousef Ahmed Alomi, Bsc. Pharm, MSc. Clin Pharm, BCPS, BCNSP, DiBA, CDE The Former General Manager of General Administration of Pharmaceutical Care, Former Head, National Clinical pharmacy and pharmacy practice, Former Head, Pharmacy R\&D Administration, Ministry of Health, Riyadh, SAUDI ARABIA.

Phone no: +966 504417712

E-mail: yalomi@gmail.com

Received: 13-12-2018;

Accepted: 10-1-2019

Copyright: ๑ the author(s),publisher and licensee Pharmacology, Toxicology and Biomedical Reports. This is an open-access article distributed under the terms of the Creative Commons Attribution NonCommercial License, which permits unrestricted non-commercial use, distribution, and reproduction in any medium, provided the original work is properly cited.

This is an open access article distributed under the terms of the Creative Commons Attribution-NonCommercial-ShareAlike 4.0 License

Access this article online

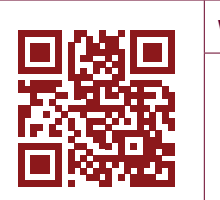

www.ptbreports.org

DOI:

10.5530/PTB.2019.5.16

\begin{abstract}
Purpose: To explore if the factors (gender, age, social status and income) affect the job satisfaction of pharmacy career in Saudi Arabia. Methods: This is a 4-month cross sectional survey regarding the impact of stress factors on job satisfaction of a pharmacist in Saudi Arabia. The survey questionnaire consisted of 35 questions divided into two parts: first part collected demographic information and the second part consisted on various sections. Section one collected information about stress factors in pharmacy job. Section two collected information about service units of the pharmacy job. Section three collected information about communication and relationship factors of a pharmacy job. Factors affected the Pharmacy practice, stress-related job and communication and relationships sections of pharmacist job satisfactions including gender, age, social status, academic qualifications and income. The questionnaire was prepared in an electronic format and the data were analyzed through the Survey Monkey system. Results: A total of 242 participants responded to the questionnaire. Of them, $214(91.8 \%)$ were Saudi and $33(8.2 \%)$ were non-Saudi professionals. Male responders were more than female responders (169 $(70.7 \%)$ and $70(29.3 \%)$, respectively). The majority of the responders (202 $(84.2 \%))$ were in the age group of 20-39 years. Females disagreed management policies more than that of males; males worked on many weekends and on holidays with significant differences when compared with females $(p<0.05)$. Responders in the age group of $30-39$ years strongly agreed to perform excessive work than those in the age group of $20-29$ years, which was found to be significant $(p<0.05)$. Both males and females wished to continue to work in the pharmacy field, which was not significantly different $(p>0.05)$. There is no significant difference between male and female with all level of salary and type work with payment or the salary resemble of other organizations $(p>0.05)$. Conclusion: Different factors were found to negatively and positively affect the job satisfaction of a pharmacist. Gender and age were found to affect job satisfaction significantly. These differences should be considered before interpreting the results of pharmacist job satisfaction. We recommend to improve the job satisfaction of pharmacists in the Kingdom of Saudi Arabia.
\end{abstract}

Key words: Stress, Factors, Job, Satisfaction, Pharmacy, Saudi Arabia.

\section{INTRODUCTION}

Pharmacists' job satisfaction is one of the measurement tools used to follow the implementation of pharmacy strategic plan at General Administration of Pharmaceutical Care, at the $\mathrm{MOH}, \mathrm{KSA} .^{1,2}$ Job satisfaction can be measured from different aspects of a pharmacist's job, including general pharmacy services, dealing with supervisor and pharmacy staff, communication with all healthcare providers, and stress and job motivation factors. ${ }^{3-6}$ All these elements can be measured through a survey questionnaire sent to the pharmacy staff. This is a subjective method, which might affect the answers; for instance; gender, age, social status, salary with benefits and academic qualifications. Previous studies have shown an association between the aforementioned factors and the differences in the answers to the job satisfaction survey. ${ }^{7-9}$ However, there are few studies that focus on other factors; otherwise, all factors discussed among the studies and without separated individual investigation. To the best of our knowledge, there are only few studies that have been conducted locally or in Gulf and Middle Eastern countries. ${ }^{10-12}$ Therefore, in this study, we aim ed to explore the factors affecting Pharmacy job satisfaction in Saudi Arabia.

\section{METHODS}

This is a 4-month cross-sectional survey related to the effect of stress factors on pharmacist job satisfaction in Saudi Arabia. The survey questionnaire consisted of 35 questions divided into two parts: the first part collects demographic information and the second part contains several sections. Section one has questions about stress factors in a pharmacy job, which includes pharmacy management policies, pharmacy stress factors, pharmacy personal time, salary and benefits and pharmacy motivational factors. Section two has questions about pharmacy services units in a pharmacy job, which includes pharmacy management structure, dispersing and patient education, clinical pharmacy services, pharmacy technology, pharmacy store and overall job satisfaction. Section three has questions about communication and relationship factors of a pharmacy job, which includes pharmacy supervisors, relationship with coworkers, pharmacists' interaction with other healthcare providers, customer interaction and overall job satisfaction. Factors that affect the Factors affected the Pharmacy practice, stress-related job and communication and relationships sections of pharmacist job satisfactions sections of pharmacist job satisfactions include gender, age, social status, academic quali- 
fications and income. In this study, we used the 5-point Likert response scale system to obtain responses; there were close- and open-ended questions. The questionnaire was prepared in an electronic format and the data were analyzed through a Survey Monkey system.

\section{RESULTS}

A total of 242 participants responded to the questionnaire. Of them, $214(91.8 \%)$ were Saudi and 33 (8.2\%) were non-Saudi professionals. Male responders were more than the female responders (169 (70.7\%) and $70(29.3 \%)$, respectively). The majority of them $(202(84.2 \%))$ were in the age group of 20-39 years. The majority of the responders were married when compared with unmarried responders (152 (66.38\%) and $75(32.75 \%)$, respectively) (Table 1). Majority of the responders had obtained a B. Pharm (114 (47.7\%)), followed by D. Pharm (81 (33.89\%)) and D. Pharm (26 (10.88\%)). Most of the responders did not have accreditation from the board of pharmaceuticals (171 (93.44\%)). The majority of the responders with current position had a designation of pharmacy technician $(80(34.93 \%))$ and staff pharmacist $(78(34.5 \%))$ and worked at outpatient pharmacy $(83(39.7 \%))$ and inpatient pharmacy $(73$ (34.9\%)). Most the responders spent less than a year (72 (30\%)), followed by $3-5$ years $(61(24.42 \%))$ and $6-10$ years $(50(20.83 \%))$ working in their current position. Most of the responders receive 7,000-12,000 SR as monthly salary (138 (58.97\%)) (Table 2). Majority of the males were in the age group of 30-39 years, whereas females were in the age group of $20-29$ years with statically significant differences $(p<0.05)$. Most of the males were married, whereas most of the females were not with statically significant difference $(p<0.05)$. The majority of the males had obtained D. Pharm, whereas most of the females had obtained B. Pharm with statically significant differences $(p<0.05)$. There were no differences between the board of pharmaceutical specialties $(p>0.05)$. Most the females were working at medical cities more than that of males with significant differences $(p<0.05)$. Most of the males had current position of pharmacy technicians or pharmacy directors, whereas most of the females worked as staff pharmacist with significant differences $(p<0.05)$. Most of the males were working at outpatient pharmacy than that of female with significant differences $(p<0.05)$. There were no differences between male and female responders related to the years of experience in pharmacy practice, clinical pharmacy and pharmacy administration $(p>0.05)$. There were no differences between male and female gender with respect to daily working hours or monthly income or long-term employment goals $(p<0.05)$. Most of the responders were in the age group of 20-29 years who work in the inpatient pharmacy than that of outpatient pharmacy with significant differences $(p<0.05)$. Most of the responders in the age group of 20-29 years had 1-3 years of experience in pharmacy practice that that of responders in the age group of 30-39 years, and most of the responders in the age group of 30-39 years had more experience in pharmacy administration with significant differences. Most of the married responders were males than that of females with significant differences and most of the females were unmarried than that of males with significant differences $(p<0.05)$. Most of the married responders were in age group of 30-39 years and 40-49 years than that of 20-29 years with significant differences $(p<0.05)$. Most of the unmarried responders were staff pharmacists working at inpatient pharmacy with significant differences $(p<0.5)$. In inpatient pharmacy, most of the responders had B. Pharm degree more than D. Pharm with significant differences $(p<0.5)$, whereas in outpatient pharmacy, most of the responders had a D. Pharm more than BPharm degree with significant differences $(p<0.5)$. The responders had a D. Pharmacy more than B. Pharm with significant differences got salary range (7000-9000 SR), whereas B. Pharm holder had more diploma holders with salary $(<6000)$ and $(>9000)$ SR.

\section{DISCUSSION}

\section{Gender factor}

According to our results, the management policy was disagreed by females more than that of males with respect to working on weekends and on holidays with significant differences $(p<0.05)$. Neutral responses were provided more by males than that of females with respect to working on weekends $(p<0.05)$. This result might be due to females being more satisfied with their schedule than that of males. This finding is contradictory to that reported by previous study. ${ }^{7,11}$ Females strongly agree that their job is challenging than that of males with significant differences. This might be because female pharmacists wish to improve pharmacy services and implement new practice programs, whereas most of the males were technicians and their main focus was toward operation rather than implementing new pharmacy services. Males agreed more than females in changing pharmacy field previously with significant differences $(p<0.05)$, which is related to the higher number of pharmacy technicians wish to change their pharmacy field, but the pharmacist did not wish to change. Without any significant differences, both males and females were continuing to work in the field of pharmacy $(p>0.05)$ because the male with old age they will change their field now. Furthermore, female pharmacy supervisors agreed more than that of male supervisors with significant differences. The supervisors provided feedback about doing the job and had adequate knowledge of their job $(p<0.05)$; this finding is similar

\begin{tabular}{|c|c|c|}
\hline Nationality & $\begin{array}{l}\text { Response } \\
\text { Count }\end{array}$ & Response Percent \\
\hline Saudi & 214 & 91.85 \\
\hline Non- Saudi & 19 & 8.15 \\
\hline Answered question & 233 & \\
\hline Skipped question & 9 & \\
\hline Gender & $\begin{array}{l}\text { Response } \\
\text { Count }\end{array}$ & Response Percent \\
\hline Male & 169 & 70.71 \\
\hline Female & 70 & 29.29 \\
\hline Answered question & 239 & \\
\hline Skipped question & 3 & \\
\hline Age & $\begin{array}{l}\text { Response } \\
\text { Count }\end{array}$ & Response Percent \\
\hline$<19$ & 0 & 0 \\
\hline $20-29$ & 87 & 42.08 \\
\hline $30-39$ & 86 & 42.08 \\
\hline $40-49$ & 26 & 12.92 \\
\hline $50-59$ & 6 & 2.92 \\
\hline$>60$ & 0 & 0 \\
\hline Answered question & 240 & \\
\hline Skipped question & 2 & \\
\hline Marital status & $\begin{array}{l}\text { Response } \\
\text { Count }\end{array}$ & Response Percent \\
\hline Single & 75 & 32.75 \\
\hline Married & 152 & 66.38 \\
\hline Other (please specify) & 2 & 0.87 \\
\hline Answered question & 229 & \\
\hline Skipped question & 13 & \\
\hline
\end{tabular}




\begin{tabular}{|c|c|c|}
\hline Academic Qualification (s): & Response Count & Response Percent \\
\hline Diploma Pharmacy & 81 & 33.89 \\
\hline Bsc. Pharm & 114 & 47.70 \\
\hline M.S & 4 & 1.67 \\
\hline Msc. Clinical Pharmacy & 16 & 6.69 \\
\hline Pharm.D. & 26 & 10.88 \\
\hline Ph.D & 2 & 0.84 \\
\hline MBA & 4 & 1.67 \\
\hline $\begin{array}{l}\text { Pharmacy Residency Two years } \\
\text { (R2) }\end{array}$ & 2 & 0.84 \\
\hline $\begin{array}{l}\text { Pharmacy Residency one year } \\
\text { (R1) }\end{array}$ & 2 & 0.84 \\
\hline Fellowship & 0 & 0 \\
\hline Other (please specify) & 3 & 1.26 \\
\hline Answered question & 239 & \\
\hline Skipped question & 3 & \\
\hline Current position & Response Count & Response Percent \\
\hline Pharmacy Technicians & 80 & 34.93 \\
\hline Lecturer & 0 & 0.00 \\
\hline Intern Pharmacist & 3 & 1.31 \\
\hline Director of Pharmacy & 22 & 9.61 \\
\hline Staff Pharmacist & 79 & 34.50 \\
\hline Supervisor Pharmacist & 21 & 9.17 \\
\hline Clinical Pharmacist & 12 & 5.24 \\
\hline Deputy Director of Pharmacy & 4 & 1.75 \\
\hline Manager & 3 & 1.31 \\
\hline Other (please specify) & 5 & 2.18 \\
\hline Answered question & 229 & \\
\hline Skipped question & 13 & \\
\hline The practice area & Response Count & Response Percent \\
\hline Inpatient Pharmacy & 73 & 34.76 \\
\hline Outpatient Pharmacy & 83 & 39.52 \\
\hline Satellite Pharmacy & 0 & 0.00 \\
\hline Narcotics & 2 & 0.95 \\
\hline Extemporaneous Preparation & 2 & 0.95 \\
\hline Clinical Pharmacy & 9 & 4.29 \\
\hline Inventory Control & 3 & 1.43 \\
\hline Drug Information & 4 & 1.90 \\
\hline Emergency pharmacy & 2 & 0.95 \\
\hline Medication safety & 2 & 0.95 \\
\hline Repacking & 0 & 0.00 \\
\hline Pharmacy Education and Training & 1 & 0.48 \\
\hline Other (please specify) & 29 & 13.81 \\
\hline Answered question & 210 & \\
\hline Skipped question & 32 & \\
\hline
\end{tabular}

\begin{tabular}{|l|c|c|}
\hline Total years in current position & Response Count & Response Percent \\
\hline$<3$ & 72 & 30.00 \\
\hline $3-5$ & 61 & 25.42 \\
\hline $6-10$ & 50 & 20.83 \\
\hline $11-15$ & 25 & 10.42 \\
\hline$>15$ & 32 & 13.33 \\
\hline Answered question & 240 & \\
\hline Skipped question & 2 & \\
\hline Monthly income & Response Count & Response Percent \\
\hline$<6.000$ & 16 & 6.84 \\
\hline $7.000-9.000$ & 56 & 23.93 \\
\hline $10.000-12.000$ & 82 & 35.04 \\
\hline $14,000-16,000$ & 43 & 18.38 \\
\hline $18,000-20,000$ & 26 & 11.11 \\
\hline$>25.000$ & 11 & 4.70 \\
\hline Answered question & 234 & \\
\hline Skipped question & 8 & \\
\hline
\end{tabular}

to a previous study. ${ }^{7}$ May be because the supervisor was female pharmacist and take care with pharmacy work of the pharmacist, not pharmacy technicians. Male responders more strongly disagreed than that of female responders with significant differences in the supervisor teach the pharmacist proper dealing with the patient $(p<0.05)$; this might be because males at outpatient department were working with high workload helped them to properly deal with patients. Females agreed more than males in identifying the unavailable product with significant differences $(p<0.05)$; this might be because females working at inpatient department knew more about the demand for some very critical medications, which led to prevention of shortage medications. Females significantly agreed more than males with respect to the salary they received, whereas males were more neutral than female with significant differences $(p<0.05)$; this might be because females were younger and new to their job, whereas males were older and more responsible and demanded higher salary than that of females. Females were more satisfied than males with respect to their salary with significant differences $(p<0.05)$.

According to our results, females significantly agree more than males that physicians do not cooperate with respect to job-related matter $(p<0.05)$. That might be because the female pharmacist more contacting physicians and correction their mistake at inpatient pharmacy while male pharmacy technicians not discussed a lot or stop their mistake. While nurses cooperated more than physicians and nurses were consulted more than the pharmacy technicians. As a result, females disagreed more than males with significant differences with nurses, they were not cooperative related job matter $(p<0.05)$. Moreover, females agreed more than males with significant differences with nurses consultation the pharmacy staff while male more neutral than female in pharmacy consultations $(p<0.05)$. Females agreed more than males with significant differences with patients' appreciation, while the male more neutral than the female with significant differences in patients' appreciation $(p<0.05)$. This is expected because the pharmacist counselled the patients and males did not do so.

Females significantly disagreed more than males with respect to working more or a higher number of prescriptions, job stress associated, which may affected negatively to the quality of work or friend relationship $(p<0.05)$. This result is contradictory with that of a previous study. ${ }^{7,11}$ This is because more females worked at inpatient pharmacy with less work- 
load than that of females working in the outpatient pharmacy. Moreover, the majority of work was done by pharmacy technicians, whereas pharmacists only double-check or follow-up the pharmacy technician work. Females significantly agreed more than males regarding to take a break during the day, whereas females significantly disagreed more than male with respect to work contribution at a successful organization $(p<0.05)$. The female had a sufficient time for rest while male maybe not had rest and relaxation room. Despite that pharmacists experienced job satisfaction in various factors, some factors did not reach optimal satisfaction such as performance contribution based on the organization's strategic plan.

\section{Age Factor}

With respect to age factor pharmacists in the age group of 30-39 years strongly agreed with more significant differences than age 20-29 years in the excessive work and elements of staff inadequate to cover the workload $(p<0.05)$ that's similar to previous study. ${ }^{7}$ Most of the pharmacists in the higher age group had more experience in pharmacy, and most of them had more experience in leadership and in administration. Pharmacists in the age group of 30-39 years faced more administrative problems than those in the age group of 20-29 years with significant differences $(<0.05)$. The age $30-39$ years strongly disagree more than age 20-29 years had more time for continuous education or maintaining professional competency with significant differences $(p<0.05)$. Pharmacists in the higher age group category needed more education and training to update their knowledge and skills. Pharmacists in the age group of 30-39 years experienced more prescription-related problems than those in the age group of 20-29 years with significant differences.

In addition, in age 30-39 years more agree than age 20-29 years that's stress job affected negatively on mental and emotional health while age 20-29 years not agree with that is one and with significant differences $(p<0.05)$. The higher age pharmacy staff had more workload and facing challenges and problems that are affected the emotional health; while the younger age pharmacist had not all previous problems. In an age 30-39 years more strongly disagree than age 20-29 years in providing education for healthcare professionals with significant differences $(p<0.05)$, the older age pharmacist may be provided education sessions to healthcare providers while the new pharmacist did not provide it they need more experience and skills of pharmacy lectures delivery.

\section{Social Factor}

Most of the single responders strongly disagree than married with significant differences between $f$ the kind of work with the amount paid or the salary resemble with other organizations or salary satisfaction $(p<0.05)$. It strange that is not married responders need more salary than a married one because they are younger age and need more money to meet all social needs. The married responders more disagree than single with significant differences in term of had a flexible schedule $(p<0.05)$ that's similar to previous study. ${ }^{7}$ Because the married responders need a more flexible schedule to need social needs. The married responders more agreed than single responders with significant differences in job stress affected negatively with mental and emotional health while the single responders not so $(p<0.05)$, while the married responders disagree with job stress affected negatively with friend relationships with significant differences $(p<0.05)$. That is related to both emotionally related problems of job and social life. However, those factors will not affect the friend relationship. The responders may be relaxed with their friends than a job.

\section{Salary and income Factor}

There is no significant difference between male and female with all amount of salary and type work with payment or the salary resemble of other organizations $(p>0.05)$. While the high salary of level $14,000-$
16,000 SR more satisfied than 10,000-12,000 SR with statically significant difference $(p<0.05)$, that is expected higher salary more satisfied that's similar to previous study. ${ }^{12,13}$

\section{Academic qualifications}

There were no significant differences between the various factors related to academic qualifications and job satisfaction (facing job challenges, changing pharmacy field, or career) $(p>0.5)$; this result agrees with that of a previous study ${ }^{13}$ and is contradictory to another study. ${ }^{11}$ That is mainly decreases or increases of academic qualifications will affect pharmacy career satisfaction. Moreover, the number of responders with B. Pharm were more than those with D. Pharm. Most of the responders had B. Pharm or D. Pharm. This shows that there are some differences between the B. Pharm or D. Pharm holder in many aspects. First, B. Pharm holders significantly disagreed more than $\mathrm{D}$. Pharm holders with respect to their freedom of work $(p<0.5)$. Moreover, because of the regulations and procedures in the pharmacy field, the pharmacists experienced more restrictions in their job responsibilities than that of pharmacy technicians. The pharmacy diploma holders agreed more than B. Pharm holders with supervisor qualified supervision and can provide pharmacy technician information about doing work more than pharmacists $(p<0.5)$. The pharmacy technician required more medication information than pharmacist. While the B. Pharm holder lesser required for information from their supervisors of the boss had same academic qualifications. B. Pharm holders significantly agreed more than D. Pharm with respect to their salaries; the pharmacist maybe had excessive work than diploma holder, more responsibility and more money required for their performances. In general, our results did not show significant differences with respect to academic qualifications and the salary paid in organizations and more salary satisfaction $(p>0.5)$. The BSc. Pharm holders significantly agreed more than diploma in pharmacy holders related to the non-pharmacist performing the duties of a pharmacist $(p>0.5)$. The pharmacist had more activities and responsibility than diploma holders.

B. Pharm holder significantly disagreed more than diploma in pharmacy holders with respect to patient appreciations and the patients lessen to pharmacist instructions $(p<0.5)$. The pharmacists were more familiar with patient's condition and monitored their drug-related problems than that of pharmacy technicians. The pharmacy diploma holders significantly agreed more than $\mathrm{B}$. Pharm holders with excess work and the high number of prescriptions $(p<0.5)$. This result is expected because of the operation of medication preprations done by pharmacy technicians. B. Pharm holders significantly disagreed more than pharmacy diploma holders with respect to job stress associated with quality of work $(p<0.5)$; this is related to stress, responsibility and administrative issues.

\section{CONCLUSION}

Pharmacists job satisfaction was found to be negatively or positively affected by various factors related to their job. Gender and age were the most influential factors, whereas social status affected less. It should be considered all internal and external factors can affected job satisfaction to explore the real picture of findings in the pharmacist job satisfaction analysis.

\section{ACKNOWLEDGEMENT}

None.

\section{CONFLICT OF INTEREST}

The authors declare no conflicts of interest. 


\section{ABBREVIATIONS}

KSA: Kingdom of Saudi Arabia; MOH: Ministry of Health; Bsc: Pharm, Bachelor of Science in Pharmacy; Pharm D: Doctor of Pharmacy.

\section{ORCID ID}

Yousef Ahmed Alomi (iD https://orcid.org/0000-0003-1381-628X

\section{REFERENCES}

1. Alomi YA, Alghamdi SJ, Alattyh RA. Strategic Plan of General Administration of Pharmaceutical Care at Ministry of Health in Saudi Arabia 2012 - 2022. JPharm Pharm Scien. 2015;1(13):1-8.

2. Alomi YA, Alghamdi SJ, Alattyh RA, Elshenawy RA. The Evaluation of Pharmacy Strategic Plan in Past 2013-2016 and Forecasting of New Vision 2030 at Ministry of Health in Saudi Arabia. J Pharm Pract Community Med. 2018;4(2):93-101.

3. Kuiper RL, Cowan DLP, Pacitti R. Job satisfaction in hospital pharmacists. Am J Heal Pharm. 2011;68(2):115

4. Suleiman A. Stress and job satisfaction among pharmacists in Riyadh, Saudi Arabia. Saudi J Med Med Sci. 2015;3(3):213.
5. Bawazir SA. Job satisfaction in Saudi community pharmacists. J Pharm Pract Res. 2005;35(4):334.

6. McCann L, Hughes CM, Adair CG, Cardwell C. Assessing job satisfaction and stress among pharmacists in Northern Ireland. Pharm World Sci . 2009 ;31(2):188-94

7. Carvajal MJ, Popovici I. Gender, age, and pharmacists' job satisfaction. Phar macy Practice. 2018; 16(4):1-11.

8. Vivek J, Priya R, Shubhi P, Shilpi R, Preeti S, Ashuthosh P, et al. Evaluation of Job Satisfaction \& Social Identity of Rural Indian Pharmacist. Indian J Pharm Pract. 2013;6(1):47-58.

9. Maio V, Goldfarb NI, Hartmann CW. Pharmacists ' Job Satisfaction : Variation by Practice Setting. Pharm Ther. 2004;29(3):184-90.

10. Slimane NSB. Motivation and Job Satisfaction of Pharmacists in Four Hospitals in Saudi Arabia. J Health Manag. 2017;19(1):39-72.

11. Balkhi B, Alghamdi A, Alshehri N, Alshehri A. Assessment of job satisfaction among hospital pharmacists in Saudi Arabia. IOSR J Pharm. 2017;7(5):34-40

12. Zahrani F, Ghamdi M, Ahmad R. Job Satisfaction among Retail Pharmacists in Eastern Region of Saudi Arabia. J Pharm Res Int. 2017;19(5):1-12.

13. Mengesha M, Tigabu BM. Job satisfaction of pharmacists in Ethiopia: The case of Harar town. Int J Pharm Pharm Sci. 2014;6(9):449-52. 